\title{
Simulasi dan Analisis Electrodynamic Shaker untuk Pengujian Dinamis A-Arm pada Sapuangin Speed
}

\author{
Devi Maharani Kosa dan Harus Laksana Guntur \\ Departemen Teknik Mesin, Fakultas Teknologi Industri, Institut Teknologi Sepuluh Nopember (ITS) \\ e-mail: haruslg@me.its.ac.id
}

\begin{abstract}
Abstrak-A-arm merupakan salah satu komponen suspensi yang berperan penting saat mobil balap melaju. Pada kompetisi mobil balap Student Formula Japan, a-arm dari mobil Sapuangin Speed perlu dilakukan modal testing sebagai bagian dari ketentuan awal lomba. Pemilihan shaker yang spesifik sangat krusial untuk mendapatkan data modal testing dengan akurasi tinggi. Electrodynamic shaker (ES) merupakan salah satu sistem yang dirancang untuk mengetahui karakteristik dinamis suatu elemen setelah dikenai beban. ES dapat menganalisis karakteristik dinamis dari sebuah $a$-arm sebelum kompetisi dimulai, sehingga kegagalan pada a-arm, seperti terjadinya bending yang berlebihan atau patah, dapat dihindari. Oleh karena itu, untuk memperoleh desain ES yang sesuai untuk pengujian a-arm dari Sapuangin Speed, perlu dilakukan simulasi dan analisis terhadap ES. ES dirancang berdasarkan acuan shaker yang sudah ada di pasaran dan memiliki sistem translasi sederhana. Pada rancangan ini, parameter dinamis dari shaker dicari dan disesuaikan dengan karakteristik dari a-arm. Simulasi, dengan bantuan perangkat lunak Simulink MATLAB R2013, dilakukan dengan input sinusoidal untuk mendapatkan parameter redaman dari shaker. Input arus yang digunakan adalah sebesar 12.5 A dengan frekuensi listrik $50 \mathrm{~Hz}$. Untuk mengetahui respon sistem saat terkena perubahan input arus dilakukan variasi nilai yang berbeda yaitu sebesar $12.5 \mathrm{~A}, 10.5 \mathrm{~A}$, dan $14.5 \mathrm{~A}$. Selain itu, dua material objek uji dipilih (steel dan carbon fiber) untuk mengetahui respon sistem terhadap material komponen uji yang berbeda. Penelitian menunjukkan bahwa peningkatan besar arus berbanding lurus dengan besarnya nilai respon perpindahan, kecepatan, dan percepatan $E S$ dan $a$-arm. Sedangkan perbedaan respon dinamis perpindahan pada carbon fiber lebih kecil daripada steel karena carbon fiber memiliki kekakuan yang lebih tinggi. Selain itu, dari simulasi didapatkan parameter redaman shaker yang ideal sebesar $5000 \mathrm{Ns} / \mathrm{m}$.
\end{abstract}

Kata Kunci-A-Arm, Arus, Electrodynamic Shaker, Sapuangin Speed, Translasi.

\section{PENDAHULUAN}

$\mathrm{I}$ NSTITUT Teknologi Sepuluh Nopember (ITS) merupakan salah satu peserta kompetisi mobil formula internasional, Student Formula Japan, yang diselenggarakan oleh Japan Society of Automotive Engineer. Mobil yang mengikuti lomba harus didesain sedemikian rupa untuk memenuhi kriteria dan dapat memberikan performa optimal. Mobil balap formula dibangun dari rancangan mobil yang disederhanakan dari mobil balap Formula One, yang mana didesain dan dibangun sendiri oleh mahasiswa-mahasiswa ITS untuk keperluan kompetisi.

Electrodynamic shaker (ES) merupakan sistem yang dirancang untuk mengetahui karakteristik dinamis suatu elemen setelah dikenai beban. $E S$ yang dirancang berdasarkan acuan shaker yang sudah ada dan memiliki sistem translasi sederhana. Rancangan shaker ini dapat menganalisa karakteristik dinamis dari sebuah $a$-arm terlebih dahulu untuk menghindari kegagalan pada a-arm seperti terjadinya bending atau patah akibat menahan beban kendaraan. A-arm merupakan salah satu komponen suspensi yang berperan penting saat mobil balap melaju. Hasil analisa karakteristik dinamis $a$-arm dibutuhkan untuk kesesuaian ketika penyetelan a-arm ke body kendaraan dan perlu dilakukan modal testing oleh ES pada a-arm untuk melakukan analisa. Pemilihan shaker yang spesifik sangat krusial untuk mendapatkan data modal testing dengan akurasi tinggi serta menghasilkan rancangan a-arm yang handal. Parameter dinamis dari shaker dicari dan disesuaikan dengan karakteristik dari $a$-arm.

Pada tahun 2016, Murtadlo menganalisis kekuatan dan umur kelelahan desain a-arm tube dari mobil formula Sapuangin Speed menggunakan metode elemen hingga. Dengan penelitian ini, diperoleh desain yang tepat untuk a-arm mobil Sapuangin Speed dan mampu melalui tes statis maupun dinamis pada ajang kompetisi Student Formula Japan. Sedangkan untuk pengembangan ES, Hickey dkk. (2013) melakukan studi terhadap ES dan memperoleh pemodelan ES pada free body diagram. Pada tahun 2015, Harris dkk. membahas dan memperoleh pemilihan stinger yang ideal untuk sebuah ES.

Pada penelitian ini dilakukan simulasi dengan input sinusoidal menggunakan software MATLAB Network R2013a untuk mendapatkan parameter redaman yang ideal dari $E S$.

\section{METODE PENELITIAN}

Dalam penulisan tugas akhir ini diperlukan referensireferensi yang dapat menunjang dalam menganalisis rancangan ES untuk pengujian A-Arm. Masalah yang diidentifikasi pada penelitian ini ada dua, yaitu input dan output. Input yang diberikan berupa variasi arus, variasi material, dan konstanta redaman. Sedangkan output yang dihasilkan dari penelitian ini adalah respon dinamis yang dihasilkan oleh sistem. Input arus yang digunakan adalah sebesar 12.5 A dengan frekuensi listrik $50 \mathrm{~Hz}$. Untuk mengetahui respon sistem saat terkena perubahan input arus dilakukan variasi nilai yang berbeda yaitu sebesar 12.5 A, 10.5 A, dan 14.5 A. Selain itu, untuk mengetahui respon sistem yang menggunakan material komponen uji yang berbeda, 
dilakukan juga variasi material objek uji dengan material steel dan carbon fiber.

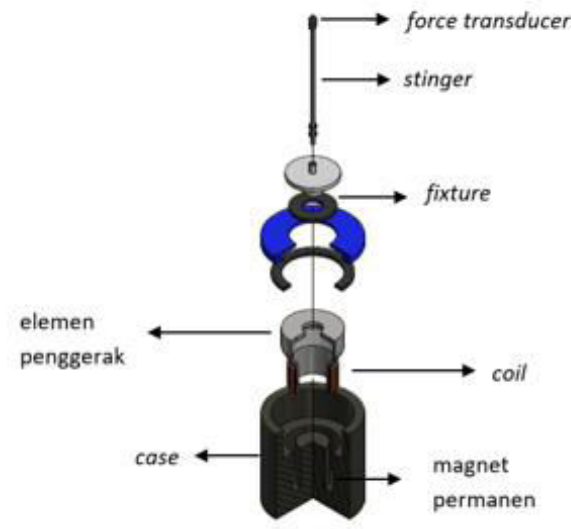

(a)

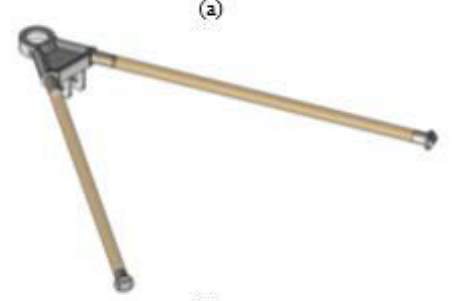

(b)

Gambar 1. Model fisik (a) ES yang akan digunakan dengan system translasi dan (b) susunan front upper a-arm pada Sapuangin Speed.

ES yang akan dirancang memiliki sistem translasi dan merupakan sistem yang paling sederhana namun mampu memenuhi kriteria pengujian modal analysis.

Tabel 1.

Parameter yang digunakan dalam perancangan ES

\begin{tabular}{ccc}
\hline \hline Parameter & Simbol & Nilai \\
\hline Massa ES $(\mathrm{kg})$ & $\mathrm{M} 1$ & $6 \mathrm{~kg}$ \\
Massa a-arm (kg) & $\mathrm{M} 2$ & $0.468 \mathrm{~kg}$ \\
Shaker stiffness (N/m) & $\mathrm{k} 1$ & $2600 \mathrm{~N} / \mathrm{m}$ \\
A-arm stiffness (N/m) & $\mathrm{k} 2$ & $27086813.24 \mathrm{~N} / \mathrm{m}$ \\
A-arm damping (Ns/m) & $\mathrm{c} 2$ & $1427.12 \mathrm{Ns} / \mathrm{m}$ \\
Electromechanical coupling & $\alpha$ & 26.68 \\
Hambatan listrik & $\mathrm{R}$ & $0.5 \Omega$ \\
Stinger stiffness (N/m) & $\mathrm{k}_{\mathrm{s}}$ & $129877040 \mathrm{~N} / \mathrm{m}$ \\
\hline \hline
\end{tabular}

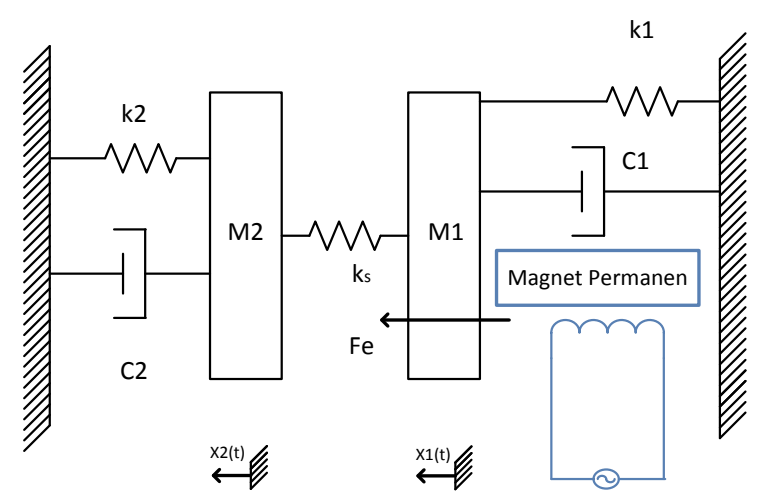

Gambar 2. Model dinamis electrodynamic shaker dan A-arm

Pada rancangan ES seperti pada gambar 1(a) digunakan fixture atau flexible support pada bagian atas shaker. Umumnya digunakan rubber membrane pada mayoritas shaker yang sudah ada sehingga dengan konstanta kekakuan yang telah tertera pada katalog dilakukan simulasi dengan Autodesk Inventor software untuk analisa tingkat keamanan flexible support. Gerak translasi sistem dihasilkan oleh gaya eksitasi (gaya elektromagnetik). Adapun gaya eksitasi tersebut terjadi akibat sistem elektrik pada ES. Gaya tersebut dihasilkan oleh medan magnet dari kumparan yang dilewati oleh arus. Setelah membuat pemodelan sistem dinamis seperti pada gambar 2, dilanjutkan dengan pembuatan persamaan gerak untuk analisa tersebut dengan membangun free body diagram dari model fisik yang sudah disederhanakan. Persamaan state variable yang dihasilkan dari pemodelan dinamis kemudian diubah mejadi blok diagram simulasi dengan software MATLAB Network R2013a. Simulasi ini dilakukan untuk mendapatkan penyelesaian persamaan matematis dari pemodelan sistem ES beserta objek uji. Setelah pembuatan blok diagram, dilanjutkan dengan simulasi. Simulasi pada pemodelan sistem $E S$ dimulai dengan input yang digunakan berupa gaya sinusoidal, sehingga menghasilkan output berupa displacement pada massa utama $\left(\mathrm{x}_{1}\right)$ yang akan menjadi input pada objek uji yang menempel pada massa utama. Output pada objek uji berupa a-arm seperti pada gambar 1(b) yang dihasilkan adalah displacement $\left(\mathrm{x}_{2}\right)$. Kedua pemodelan tersebut menghasilkan respon dinamis dari sistem. Nilai c (damping coefficient) pada ES dengan metode trial dan error yang nantinya akan digunakan sebagai nilai parameter pada blok diagram sistem yang telah dibuat di MATLAB Simulink. Dari simulasi sistem rancangan ES dengan input redaman dari sistem, akan didapat respon dinamis berupa perpindahan dari input sinusoidal sesuai dengan karakteristik a-arm dengan memodifikasi blok diagram pada Simulink. Karakteristik a-arm disesuaikan dengan output simulasi yang menghasilkan displacement sebesar $3 \times 10^{-5} \mathrm{~m}$. Flexible support yang digunakan adalah rubber membrane dengan ketebalan 0,15 inch dan stiffness coefficient sebesar $2600 \mathrm{~N} / \mathrm{m}$. Setelah didapatkan model dinamis, maka selanjutnya diperoleh persamaan gerak dari sistem tersebut seperti berikut:

Persamaan State Variable Sistem ES

$$
\dot{v} 1=\frac{1}{M 1}[-(k 1+k s) x 1-c 1 v 1+k s x 2+\alpha i]
$$

Persamaan State Variable Sistem A-Arm

$$
\dot{v} 2=\frac{1}{M 2}[-k 2 x 2-c 2 v 2+k s \times 1-k s \times 2]
$$

Persamaan State Variable Sistem Elektris ES

$$
i=\frac{1}{R}\left[e_{i}(t)-L \frac{d i}{d t}-\alpha\left(\dot{x}_{1}-\dot{x}_{2}\right)\right]
$$

Input sinusoidal digunakan untuk melihat respon dinamis massa utama akibat beban harmonik, serta untuk melihat waktu yang dibutuhkan sistem untuk mencapai kondisi steady state. Gaya yang bekerja pada komponen A-Arm merupakan gaya yang didapatkan dari mekanisme ES.

Gaya tersebut merupakan input sinusoidal yang mampu merepresentasikan gaya eksitasi dinamis shaker. Pada simulasi ini juga kemudian dilakukan metode trial dan error untuk mendapatkan nilai redaman yang sesuai untuk sistem. Dari 
input ini didapatkan respon dinamis dari sistem ES dan komponen A-Arm.

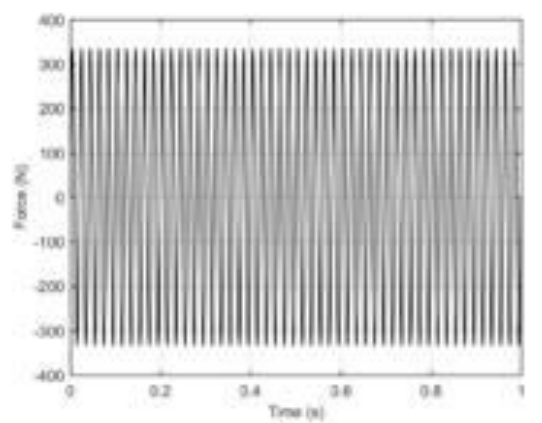

(a)

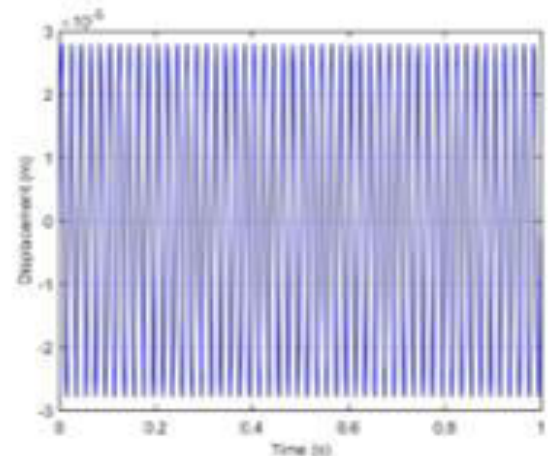

(b)

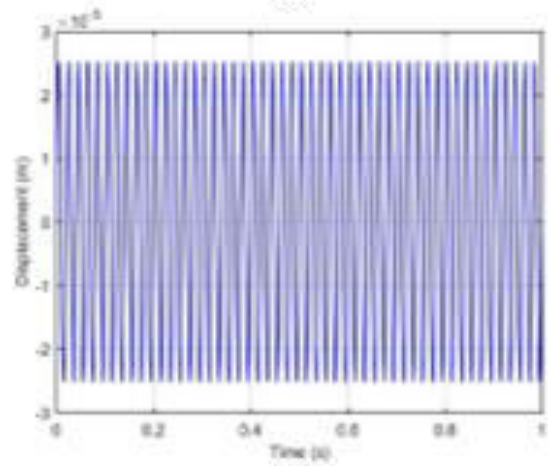

(c)

Gambar 3. Output berupa (a) gaya elektris electrodynamic shaker, (b) respon perpindahan electrodynamic shaker, dan (c) respon perpindahan a-arm

\section{HASIL DAN PEMBAHASAN}

Dapat dilihat dari gambar 3 bahwa respon perpindahan dari $E S$ mempunyai hasil yang lebih besar dibandingkan a-arm. Pada grafik hasil simulasi sistem menunjukkan bahwa objek uji memiliki respon perpindahan lebih kecil daripada shaker. Hal tersebut dapat disebabkan karena objek uji memiliki stiffness yang lebih besar. Selain itu, respon perpindahan shaker lebih besar karena gaya elektris terlebih dahulu dikenakan ke shaker dan kemudian diteruskan ke objek uji. Untuk pengaruh stinger hampir tidak ada karena rancangan stinger yang digunakan memiliki kekakuan yang sangat tinggi sehingga tidak menyebabkan perpindahan tambahan yang besar dari x1 terhadap x2. Pada simulasi ini juga kemudian ditemukan nilai redaman yang ideal untuk sistem ES yang dirancang adalah sebesar $5000 \mathrm{Ns} / \mathrm{m}$.

\section{KESIMPULAN}

Pada penelitian ini telah dirancang sistem untuk pengujian dinamis A-Arm pada Sapuangin Speed yang memiliki koefisien stiffness oleh flexible support sebesar $2600 \mathrm{~N} / \mathrm{m}$ dengan tebal 0,15 in dan koefisien damping sebesar 5000 $\mathrm{Ns} / \mathrm{m}$. Getaran yang terjadi pada sistem ini hanya terjadi pada arah translasi. Berdasarkan hasil simulasi dan analisis pada sistem ES serta komponen a-arm, maka dapat disimpulkan bahwa :

1. Desain akhir didapatkan bahwa damping yang terdapat pada ES tidak hanya disebabkan oleh viscous damping pada shaker gap karena hasil perhitungan redaman hanya dengan viscous damping tidak proporsional untuk dimanufaktur.

2. Pada simulasi respon dinamis dengan input sinusoidal ditunjukkan bahwa objek uji memiliki respon perpindahan lebih baik daripada shaker itu karena nilai dari respon perpindahannya lebih kecil. Objek uji memiliki respon perpindahan lebih baik karena memiliki stiffness yang lebih besar. Respon perpindahan shaker lebih besar karena gaya elektris terlebih dahulu dikenakan ke shaker dan kemudian diteruskan ke objek uji. Untuk pengaruh stinger hampir tidak ada karena rancangan stinger yang digunakan memiliki kekakuan yang sangat tinggi sehingga tidak menyebabkan perpindahan tambahan dari shaker terhadap a-arm.

\section{DAFTAR PUSTAKA}

[1] S. S. Rao, Mechanical Vibrations, Fifth Edition, 1 Lake Street, Upper Saddle River, Nj 07458: Pearson, 2011.

[2] Practical Aspects of Shaker Measurements for Modal Testing, Usa: Proceedings of Isma, 2010.

[3] Goshen, "Mengenal Mikrofon Dan Tipe Kerjanya," [Online]. Available: http://www.Goshen.Co.Id/Detailberita/390-MengenalMikrofon-Tipe-Dan-Cara-Kerjanya..

[4] C. Cobi, "Design of A Carbon Fiber Suspension System for Fsae Applications," Semantic Scholar, 2012.

[5] H. A. Murtadlo, "Analisis Kekuatan Carbon Fiber Tube A-Arm Sapuangin Speed Dengan Metode Elemen Hingga," 2016.

[6] T. M. Shop, "Modal Shaker Selection Guide," [Online]. Available: Http://Www.Modalshop.Com/Excitation.Asp?P=Modal_Shaker_Select ion_Guide\&Id=344.

[7] D. M. A. John W. M. Bush, "Generating Uniaxial Vibration with An Electrodynamic Shaker And External Air Bearing," Science Direct, 2015.

[8] F. P. D. M. Barbieri, "Complex Dynamics of Circular Cylindrical Shells," Elsevier, 2014.

[9] T. S. O. A. E. O. Japan, "2017 Student Formula Japan," The Society of Automotive Engineers of Japan (Jsae), [Online]. Available: Http://Www.Jsae.Or.Jp/Formula/En/About.Html. [Accessed Tuesday April 2017].

[10] O. M. Engineers, Formula Student, Silverstone, 9-13 July 2014

[11] G. F. Lang, "Sound and Vibration," Electrodynamic Shaker Fundamentals, P. 1, April 1997.

[12] Standards Secretariat, Acoustical Society of America. Methods for The Experimental Determination of Mechanical Mobility, Part Two: Measurements Using Single-Point Translational Excitation. (Ansi Standards S2.32-1982), New York: Acoustical Society of America, 1982.

[13] A. P. N. Vivekanandan, "Design, Analysis and Simulation Of Double Wishbone Suspension System," June 2014.

[14] S. S. W. M. I. E. Daryl Hickey, "A Study of the Electrodynamic Shaker," International Conference On Vibration Problems, 2013. 
